\title{
Exploration of a Solution-Centric Crime Awareness Tool
}

\author{
Saumya Srivastava \\ Department of Informatics \\ University of Petroleum and Energy University of Petroleum and Energy \\ Studies, Dehradun, India \\ Kashish Srivastava \\ Department of Systemics \\ Studies, Dehradun, India
}

\author{
Nitin Arora \\ DPT, Electronics \& Computer \\ Discipline \\ Indian Institute of Technology, \\ Roorkee, India
}

\begin{abstract}
In this era of modernization, people are blessed with several computers; nevertheless, it too acts as a bane to society. Not only it impacts our youth socially and emotionally, but also physically. Computers are made to perform the computations that are not easy for a normal human brain to understand and make connections all over the world. With connections, humans also bring negative aspects that result in cybercrimes such as data theft, financial frauds, phishing attacks, cyber grooming, etc. and crimes such as acid attacks, rapes, molestation, child labor, assault, etc. Therefore, in this paper, the authors will explore the need fora solution-centric crime awareness tool that understands different types of cybercrimes, more specifically crimes against women and children, website crimes, social media crimes, etc. Moreover, their reasons, causes, and solutions at the best of understanding for a child and an older adult. It also includes the precautions for an individual to stay safe and stay aware of all the governmental agencies and NGOs for women and children. Knowing about an incident or being a victim of a crime and not reporting it is equal to promoting crimes in society. So, this approach motivates people to speak up as it is okay to ask for help.
\end{abstract}

\section{General Terms}

Cyber Awareness, Cyber Security, Solution-Centric Crime Awareness Tool.

\section{Keywords}

Crime, Awareness, Cybercrime, Cyber Security, Cyber Attack, Precaution, Tool, Solution, Safety, Fraud, Un-secured Internet, Phishing, Crime-rate analysis, and Cyber Awareness

\section{INTRODUCTION}

A direction-driven online portal is the need of the hour, i.e., a tool to spread effective, compelling, and supportive information to the residents regarding Cyber Security. For this, a device can come up in the form of a web-app or mobile app. The purpose of a simple yet effective website is not to only provide advice, but to additionally bestow names of NGO's and Toll-free numbers, with the goal that the client isn't just bound to the data yet can also counsel and report to other government entities. Utilizing a Chatbot as a means of correspondence, users could be provided with practical solutions, preventions, and causes of the crime. As innovative as it gets, the tool can likewise show various graphically made posters to spread data just as to rouse others to report every single wrongdoing they have witnessed.

The combination of posters, writeups, and chatbot permits us to amalgamate visual and textual information into a convincing narrative and well-presented information from a different perspective.

\section{WHY IS A SOLUTION-CENTRIC AWARENESS TOOL REQUIRED? \\ 2.1 Increase of crime rate}

The internet has become a place filled with malicious links, viruses, fake information, honeypots, and trojans. Gathering user information has become a much easier task compared to the early recent years [1]. The clients are entirely clueless and defenseless. Even a single click can cost them thousands of rupees and sometimes millions too. In such a scary state, people need a significant resource to help them and caution them by assisting safe browsing. However, it's not merely the enormous organizations and associations that get hit. Familiar, regular users experience phishing plans, ransomware assaults, wholesale fraud, information breaks, and budgetary misfortunes. Frankly speaking, there's nothing more needed than five minutes to hack a web associated gadget, which incorporates a person's cell phone, smartwatch, on-board car $\mathrm{PC}$, brilliant TV, and home control frameworks.

\subsection{Lack of awareness and accessibility}

Moreover, as aforementioned, whenever a user is attacked, they are nothing but clueless as to what to do [2]. They neither realize where to report, nor do they comprehend that earlier reporting can help recover them their data or money. The other strand of people is the ones that are scared to come up because of the lack of support that prevails in the society and the sentiment of shame that they want to save themselves from [3].

\subsection{Unavailability of solution-centric platform}

A direction driven online portal is not available, meaning to spread effective, compelling, and supportive information to the residents of India regarding Cyber Security is lacking [4]. The purpose of a simple yet effective tool is not to only provide advice, but to additionally bestow names of NGO's and Toll-free numbers, with the goal that the client isn't just bound to data yet can also counsel and report to other government entities.

\section{ANALYZING COLLECTED INFORMATION ABOUT DIFFERENT CRIMES}

With passing time, crime has taken a different curve. It could be better understood while analyzing the crime clock statistics for different consecutive years- 


\begin{tabular}{|l|l|}
\hline \multicolumn{2}{|c|}{2016 CRIME CLOCK ANALYSIS } \\
\hline A Violent Crime occurred every & $\mathbf{2 5 . 3}$ seconds \\
\hline One Murder every & 30.6 minutes \\
\hline One Rape every & 4.0 minutes \\
\hline One Robbery every & 1.6 minutes \\
\hline One Aggravated Assault every & 39.4 seconds \\
\hline \multicolumn{2}{|c|}{} \\
\hline A Property Crime occurred every & $\mathbf{4 . 0}$ seconds \\
\hline One Burglary every & 20.9 seconds \\
\hline One Larceny-theft every & 5.6 seconds \\
\hline One Motor Vehicle every & 41.3 seconds \\
\hline
\end{tabular}

\begin{tabular}{|l|l|}
\hline \multicolumn{2}{|c|}{2017 CRIME CLOCK ANALYSIS } \\
\hline A Violent Crime occurred every & $\mathbf{2 4 . 6}$ seconds \\
\hline One Murder every & 30.5 minutes \\
\hline One Rape every & 3.9 minutes \\
\hline One Robbery every & 1.7 minutes \\
\hline One Aggravated Assault every & 39.0 seconds \\
\hline A Property Crime occurred every & $\mathbf{4 . 1}$ seconds \\
\hline One Burglary every & 22.6 seconds \\
\hline One Larceny-theft every & 5.7 seconds \\
\hline One Motor Vehicle every & 40.9 seconds \\
\hline
\end{tabular}

\begin{tabular}{|l|l|}
\hline \multicolumn{2}{|c|}{2018 CRIME CLOCK ANALYSIS } \\
\hline A Violent Crime occurred every & $\mathbf{2 6 . 2}$ seconds \\
\hline One Murder every & 32.5 minutes \\
\hline One Rape every & 3.8 minutes \\
\hline One Robbery every & 1.9 minutes \\
\hline One Aggravated Assault every & 39.2 seconds \\
\hline A Property Crime occurred every & $\mathbf{4 . 4}$ seconds \\
\hline One Burglary every & 25.7 seconds \\
\hline One Larceny-theft every & 6.1 seconds \\
\hline One Motor Vehicle every & 42.2 seconds \\
\hline
\end{tabular}

\begin{tabular}{|l|l|}
\hline \multicolumn{2}{|c|}{2019 CRIME CLOCK ANALYSIS } \\
\hline A Violent Crime occurred every & $\mathbf{2 7 . 0}$ seconds \\
\hline One Murder every & 34.6 minutes \\
\hline One Rape every & 3.7 minutes \\
\hline One Robbery every & 2.3 minutes \\
\hline One Aggravated Assault every & 39.4 seconds \\
\hline \hline A Property Crime occurred every & $\mathbf{4 . 7}$ seconds \\
\hline One Burglary every & 28.9 seconds \\
\hline One Larceny-theft every & 6.5 seconds \\
\hline One Motor Vehicle every & 44.3 seconds \\
\hline Source: $h t t p s: / / u c r . f b i . g o v /$ &
\end{tabular}

\section{Crimes can be broadly categorized as-}

1. Financial Frauds

- Financial Identity Theft

- Tax Evasion

- Money Laundering

- Cheque/Credit Card Fraud
2. Crime Against Woman and Children

- Women and Child Trafficking

- Dowry Death

- Rape/ Molestation

- Mental Harassment

- Child Labor

- Emotional Abuse

- $\quad$ Child Pornography/ Sex Trafficking

- $\quad$ Statutory Rape

3. Cyber Terrorism/ Fake News

- Cyber Terrorism against a Community/ Person/ Territory

- $\quad$ Fake News and Rumors

- Hated Comments/ Posts/ Speech

4. Physical Attack

- Modification of Data

- Theft of Information stored in electronic form

- Hampering security assets of an organization

- Theft of electronic devices

5. Website Crimes

- Websites containing child pornography content

- Website Hacking

- Data Diddling

- $\quad$ Breach of privacy and confidentiality

6. Social Media Crimes

- $\quad$ Phishing

- Data theft/ Fake accounts on social media

- Obscenity/ Revenge Porn

- Cyber Bullying/ Stalking

- Cyber Defamation

Some names of the crime mentioned above are quite familiar, while the others are entirely new, and it often creates trouble for those who are not even aware of it.

A solution-centric tool is highly required at this moment that discusses not only these crimes and their causes but also discusses solutions, preventions, and ways to report it on the right platform.

It should be accessible and feasible for every generation in today's era, whether old or young. As these crimes are not bounded to one generation, so similarly, the solution-centric crime awareness tool shouldn't be bounded as well. A highly user-friendly plan of action is needed at this time. 


\section{IPC Crimes as a percentage share to total IPC Crimes}

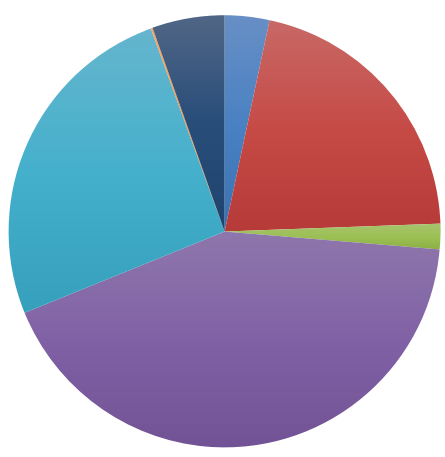

- Offences Related to Documents and Property Marks

- Miscellaneous IPC Crimes

- Offences against Property

n Offences against Public Tranquility

- Offences affecting the Human Body

- Offences against the State

ather

Fig 1: IPC Crimes as a percentage share to total IPC Crimes

4. ELABORATING DIFFERENT CRIMES based on THEIR CAUSES, PRECAUTIONS, AND SOLUTIONS

\subsection{Cheque Fraud/Credit Card Fraud} Where to Report:

- https://cybercrime.gov.in/

- http://www.cybercelldelhi.in/Report.html

- https://digitalpolice.gov.in/

Causes:

1. Skimming is a method of duplicating the credit card's information by criminals for their uses.

2. Stolen/Lost cards

3. Sharing personal information publicly

4. Phishing

\section{Precautions:}

1. Do not share personal information.

2. Keep credit/debit cards safe.

3. Use 2-factor authentication.

4. Don't sign blank receipts or papers.

5. Report lost or stolen cards.

6. Do not use public Wi-Fi for online payments.

\section{Solution:}

1. Report to the nearest Cyber Cell as soon as possible.

2. Keep changing passwords and pins frequently to prevent from fraudsters.
3. Keep a regular check on the bank reports.

4. Always keep a copy of bank or credit card reports.

\subsection{Women Trafficking} Where to Report:

- https://cybercrime.gov.in/

- https://www.prajwalaindia.com/

- The toll-free number for women in India is 1091.

Causes:

1. Poverty is one of the primary reasons behind this issue.

2. Unemployment: When the male members of the family are not working, then the females have to take the entire burden of running the household.

3. In India, child marriages still exist, and even the dowry system.

4. In the rural areas, the single, divorced, widowed, and young girls are looked down upon.

5. The states like Punjab and Haryana have a very high rate of female infanticide and female foeticide.

6. False promises and domestic violence are also significant reasons for this issue.

\section{Precautions:}

1. Support and volunteer efforts in anti-trafficking organizations.

2. Make sure that every person is well-informed regarding this sensitive crime.

3. Awareness-raising events shall be hosted where human trafficking is discussed as an essential topic.

4. Every person should be alert about the mishappenings occurring around them and report immediately to the concerned authority without delay.

\section{Solution:}

1. Work with some local communities to help stop trafficking through spreading awareness of human trafficking or a victim service provider.

2. Provide internships, skill training, jobs, and other opportunities to trafficking survivors.

3. Report to the cyber cell if the issue is very serious or directly to the police.

\subsection{Rape/Molestation}

Where to Report:

- https://cybercrime.gov.in/

- https://www.prajwalaindia.com/

- The toll-free number for women in India is 1091.

Causes:

1. Rape is caused due to the lack of decency in the person's opinions.

2. Desire to control and show dominance.

3. Revenge from an ex-partner or a friend.

4. Lack of sex-education.

5. Sexual obsession

6. Rapists don't consider the person as a human being; they see the person as an object that can be violated with impunity. 


\section{Precautions:}

1. Better CCTV mapping and policing of isolated areas is required.

2. Restructuring is needed to remove the myths associated with the clogging mind-set.

3. Avoid personal interaction with strangers.

4. Always keep some emergency contacts and safety equipment handy.

Solution:

1. Work with some local communities to help stop rape/molestation through spreading awareness.

2. Provide internships, skill training, jobs, and other opportunities for victims to overcome the trauma.

3. Report to the cyber cell if the issue is very serious or directly to the police.

\subsection{Child Labor}

\section{Where to Report:}

- https://support.savethechildren.in/

- https://cybercrime.gov.in/

- TOLL-FREE NO- 0124-4872100

Causes:

1. Poverty

2. Financial problems

3. Lack of awareness about laws

4. Unavailability to education

5. To give less employment for the work done than given to the adults

\section{Precautions:}

1. Stay aware of laws related to children.

2. Check the age of all the young employees.

3. Do not hire children below the age of 14 .

4. Educate children as they may help in improving situations by their job.

5. Create awareness about child labor.

Solution:

1. Report to the cyber cell if the issue is very serious or directly to the police.

2. Stay aware.

\subsection{Modification of Personal or} Organization's Data

\section{Where to Report:}

- https://digitalpolice.gov.in/

- https://cybercrime.gov.in/

- http://www.cybercelldelhi.in/Report.html

\section{Causes:}

1. Revenge and Jealousy

2. They have ulterior motives, for example, winning a competition.

3. A Mental condition.

4. General Hate crime.

5. For fun as a prank.

6. A means to steal data and corrupt it.

7. To get access to mail and password so that they can use them for stealing money.

\section{Precautions:}

1. Always backup data.
2. Keep the device password and encryption protected.

3. Use two-factor authentications

4. Install CCTV cameras.

5. Do not open links from unknown sources.

6. Use a firewall to avoid illegal access.

7. Setting email filters on email accounts.

8. Do not let anyone touch a personal device without permission.

Solution:

1. Report to the nearest Cyber Cell as soon as possible.

2. Try recovery options

3. Take care of not erasing the digital footprints of the criminal.

4.6 Website containing Child Pornography Content

Where to Report:

- https://digitalpolice.gov.in/

- https://cybercrime.gov.in/

- $\quad$ http://www.cybercelldelhi.in/Report.html

Causes:

1. Loneliness

2. Talking to strangers

3. Watching pornographic content

4. Cyber grooming

5. Revenge and jealousy

6. Mentality \& Psychology

7. Lack of sex education

8. Introvert and quiet

Precautions:

1. If found such content, kindly report it

2. Create awareness regarding sex education.

3. Parents should talk to their children regularly.

4. Understand and observe the child's behavior.

Solution:

1. Report to the nearest Cyber Cell as soon as possible.

2. Get counseling for the victim.

\subsection{Website Hacking and Breach of Privacy and Confidentiality \\ Where to Report:}

- http://chandigarhpolice.gov.in/cybercrime.html

- https://cybercrime.gov.in/

- http://www.cybercelldelhi.in/Report.html

Causes:

1. Data theft or personal identity theft

2. Disruption of server

3. Vulnerabilities and Unauthorized execution of codes.

4. Revenge

5. Identity Defamation.

Precautions:

1. Maintain privacy and confidentiality.

2. Tighten network security and access control. 
3. Change passwords frequently and 2-factor authentications.

4. Maintain backups regularly.

5. Keep running updates and security checks.

\section{Solution:}

1. Report to the nearest Cyber Cell as soon as possible.

2. Maintain Backup.

\subsection{Phishing}

\section{Where to Report:}

- https://cybercrime.gov.in/

- https://www.reportphishing.in/

- incident@cert-in.org.in

Causes:

1. Lack of security knowledge for users.

2. Low-cost phishing malware and ransomware are readily available.

3. Fake mails and attractive gift offer.

4. Negatively impacted organizations are a source of the attacks [5].

\section{Precautions:}

1. Educate employees about phishing kind of attacks

2. Maintain tighter security.

3. Install antivirus and firewalls for protection.

4. Encrypt all sensitive information and maintain privacy to the identities of the organization.

5. Avoid access to malicious or fake links, and use strong passwords.

Solution:

1. Change Passwords.

2. Contact the organization that was spoofed.

3. The system must be scanned for viruses.

4. Keep a check for any identity theft.

5. Report to the nearest police station.

6. Stay aware and protected from future phishing attacks.

\subsection{Cyber Defamation and Cyber}

\section{Bullying/Stalking}

\section{Where to Report:}

- https://cybercrime.gov.in/

- http://www.cybercelldelhi.in/Report.html

- $\quad$ https://help.instagram.com/1769410010008691

- https://www.facebook.com/help/contact/169486816 475808

- $\quad$ https://help.twitter.com/forms/impersonation

Causes:

1. Revenge and Jealousy

2. Pranks or for personal motive/intention

3. Hate crime and emotional abuse

4. Lack of empathy

5. Boredom becomes pain

6. Mentally unstable condition

\section{Precautions:}

1. Avoid posting personal/controversial content and maintain privacy settings.

2. Public computers should not be used for logging into personal details.

3. Educate and raise awareness.

4. Do not share other person's content without their consent.

5. Do not converse with strangers.

6. Talk to parents/elders if someone feels bullied or emotionally down.

\section{Solution:}

1. The priority is the removal of that defamatory post or media [6].

2. Report immediately to that respective website or application.

3. Save the pieces of evidence.

4. Report it to the nearest Police Station or Cyber Cell.

5. Gather evidence.

6. Block them.

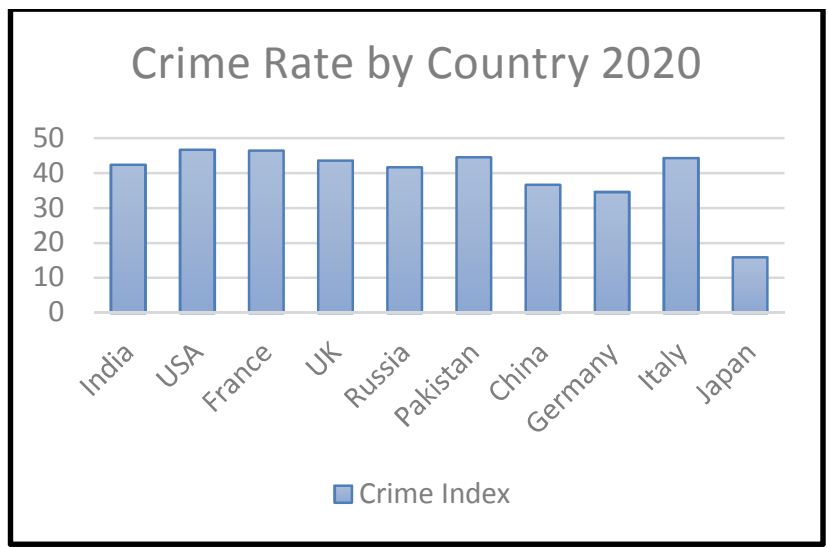

Fig 2: Crime Index for various countries

\section{PROPOSED SOLUTION/ RESULT}

Every individual is trying to find a solution by contributing as an individual, as a member in a firm, as a speaker, as a politician, as an official, or as a developer, and more. The authors would like to take the initiative to make our surroundings a happier and safe place for everyone. This proposed solution for building a solution-centric crime awareness tool is to address the challenges faced by society based on criminal activities and their solutions. Our solution centric approach is based on an online portal that is inclined to providing solutions to different kinds of crimes faced in our everyday life. Staying aware of a problem and neglecting the answers or not reporting it is a non-justifiable approach in apprehending any type of crime or assault.

The problem statement is divided into specific subproblems:

1. Accessibility

2. Lack of Awareness

3. Unavailability of Solution-Centric platform

4. Unaware of the importance of reporting the activity

5. Lack of Social Work Platform

6. Unaware of Law Enforcement Agencies

7. Unaware of solutions to a Specific Criminal Activity

Proposed solutions for the above issues can be categorized as follows in the solution-centric tool-

\subsection{A Centralized Chatbot}

One of the major solutions to the problems mentioned above 
is a centralized chatbot that would assist users as per their issues. The characteristics of the chatbot should be to direct users to the authentic governmental reporting portal, create awareness regarding the kinds of crimes and their causes along with precautions.

The chatbot should have all the generic crimes listed in it. User can report their problem by directing to the government reporting website. Also, he/she can be aware of the causes for the occurrence of the crime, solutions, and precautions for the user who might be victimized, information regarding the agencies that look after these crimes, and help the victims, knowledge of all toll-free numbers, and NGOs. The crimes that should be covered in the chatbot are Woman and Child related crimes, Website crimes, Financial frauds, Social media crimes, Fake news, and cyber terrorism, and Physical attacks. It shall cover all personal, property, statutory, and financial crimes.

\subsection{Awareness-related Articles and Blogs}

Another solution the platform should provide is to create awareness by several articles based on their meaning, causes, and solutions. These articles should be based on great visual representations posters along with write-ups on child pornography, Rape, identity theft, acid attacks, dowry, child labor, bullying, the right touch, and bad touch, etc. These articles should be written in the simple primary language for better understanding to create awareness in children and parents. They should be feasible for all age groups.

\subsection{Ease of Reporting a Crime}

Reporting of a crime is an essential part to be done even if the user is a victim or has been a part of the criminal activity indirectly. One must report any illegal activity if he/she has been a victim of the respective crime. It helps in creating awareness amongst others about the activity and to stay safe, helps in catching the attacker, understanding the psychology, and, most importantly, it helps in creating a secure environment. Several victims are present in our surroundings, aware that the suffering they have been through was a criminal activity/abuse and has to be reported. Still, due to negligence, ignorance, identity defamation, and many other reasons, activities are not reported.

Hence, the solution-centric tool should promote that a victim must always inform the activity in the nearest law enforcement firm. The users of the portal should ever be introduced to the re-direction page for reporting the activity and later on about the information related to the crime. This step should be taken by the developers to help the victims understand the importance of reporting a crime.

\subsection{Statistical Representation of Increasing and On-going Crime Rate}

A statistical representation of the common outgrowing crimes should also be stated [7]. This data will help users visualize a clear picture of the increasing rate of crimes. It will also create an insight to take precautions and in creating awareness within the community. The solution-centric portal should aim to create a society that is aware of the criminal activities happening worldwide and opting for precautions for them.

\subsection{List of NGO's}

One of the solutions that the platform should provide is to give details to the user of all the NGOs, government firms, law enforcement firms, cyber cells, and their toll-free numbers. They will help the user to get help from certain areas via an authentic firm for their problems and solutions.
The data of these firms should be an open public source data that is accessible to all.

The NGO's can be categorized into three sections-

$$
\begin{aligned}
& \text { 1. Woman and Crime } \\
& \text { 2. Children's rights } \\
& \text { 3. Cyber Crime Awareness }
\end{aligned}
$$

\subsection{Categorizing Different Crimes}

In observing this modern era where everything is being converted digitally and focusing on the current global pandemic COVID-19 that has increased the cybercrime rate exponentially, it is imperative to be aware of the different ongoing crimes [8]. In every field, whether it concerns social media or children and women, most of them face several issues. Hence the platform should also focus on covering the current scenario crimes concerning cybercrime, basically on cases based on cyberbullying, defamation, child pornography, human trafficking [9], online financial frauds, uploading obscene photos on social media, etc.

\subsection{Frequently Asked Questions}

FAQs are an essential aspect of every user-friendly tool because it covers some commonly asked questions of the audience. It should have the potential to resolve the queries of the people at the earliest. These FAQs are based on how one should take precautions and help the victim in recovering the wrong phase. Most importantly, emphasizing the fact that asking for help is a standard gesture yet an important one. Understanding emotionally as well as socially is an essential factor.

Therefore, the solution-centric crime awareness tool should aim to create awareness and help its users understand the psychology behind the crime and the causes. With the help of this platform, the best possible solutions can be proposed for the people to help them and create a safer environment.

\section{FUTURE SCOPE}

It becomes self-evident for us to make the required changes in the upcoming times with the evolving technology to be more versatile for the users.

The solution-centric tool is an awareness platform that will provide the services to get information regarding any particular type of crime.

The chatbot should be developed to help them with all the generic crimes that are listed along with providing the root causes of that crime along with precautions and the appropriate solutions/actions such as the authentic reporting portal or place, helpline numbers, and information regarding the respective NGOs which can help the individual.

In the present instance, the platform is proposed for limited crimes, or it can be said it mainly focuses on Cyber-crimes and crimes against women and children but in the upcoming instances such as:

- The portal can be launched in different multilingual languages.

- It can be a helping hand for a user in every kind of crime, whether it is related to any criminal activity, dowry cases, civil crimes like property dispute, financial dispute, family disputes, marital disputes, adoption cases, nuisance, trespass, minor offenses, contract/ agreement disputes, indemnity, guarantee, bailment, pledge, agency. 
- The root causes of these problems and enhanced precautions/awareness should also be discussed.

- We are creating awareness regarding the rights of an ordinary person in such a diverse world.

- Providing society with the awareness program about the free legal services, the law's held in-country based on the conviction to motivate the poor \& downtrodden for fighting against wrong happenings and prevailing in the society through free legal service authority.

- Besides NGOs, other governmental bodies can help people with their problems and with an appropriate solution/action required.

- In the upcoming time, the platform can be enhanced in such a way so that the users can get information regarding all the nearby police stations, cyber cells, NGOs, or other enforcement governmental bodies that would easily accessible to the victim.

- Moreover, the tool can generate a more analyzed and elaborated static report of every individual crime happening in the world along with the place/location of that crime.

Every individual wants a crime-free society for his/her family and upcoming generations. With the help of the explored platform, an aware organization can provide every necessary information to them.

\section{CONCLUSION}

The linchpin of the proposed solution-centric tool is HELP. It is an attempt to spread awareness and make it feasible for everyone to be a part of the awareness movement. The portal is the platform where anyone, despite any differences in faith, religion, caste, and creed, can ask for support in dire situations.

The key features of the tool make it even more helpful-

- The quality of the chatbot makes it easy for the person to ask questions according to their needs, along with the frequently asked questions.

- The list of the NGOs and government-operated centers gives another edge to help the person in need, and there is no limitation on age.

- The enticing posters and banners can make the tool more alluring.

- With these features, the motive is to spread the fact that "It's okay to ask for help."

Every category of crime can have a proper solution and prevention too. The aim is to not only bring the light of awareness but also to take this light forward and brighten the world. Our society is not a comfortable place to live in, many people are a target of crimes, and these innocent people are the victims of cruelty every day. Our responsibility as a citizen is to take front and help the victims of this brutality.

This tool can exude the correct way to become aware of what is happening around and why it increases at such an alarming rate. This indeed is the need of the hour. The chatbot can be helpful in many ways as it can provide a platform where the person can type their questions and get a precise and relevant answer along with the statistics of the current situation. The authors want to remove the ongoing myopia of society by emblazing HOPE.

The tool can give an insight to the people and help spread the value of awareness amongst them [10]. The main aim is to use the device as a medium to spread awareness and make it a platform where there is no shame in asking for help.

This portal can be an effort towards the betterment of this society.

\section{ACKNOWLEDGMENTS}

The authors thank their colleagues from Gurugram Police Cybersecurity Internship, who provided insight and expertise that greatly assisted the research. They thank them for the comments that significantly improved the manuscript. The authors would also like to show their gratitude to Mr. Rakshit Tandon, Mentor/Director/Founder, Gurugram Police Cyber Security Internship, for sharing his pearls of wisdom during this research.

\section{REFERENCES}

[1] Ms.Arpan and Dr.Meenal Chauhan, "Preventing Cyber Crime: A Study Regarding awareness of cybercrime in Tricity," 2012 International Journal of Enterprise Computing and Business Systems, 2012.

[2] Madeleine Jarrett-Luck, "Reconceptualising Fear of Crime: The Emergence of Crime Awareness," 2017 Bond University, (The Responsibilisation of the Individual) 2017.

[3] Mirdul Sharma and Satvinder Kaur, "Cyber Crimes Becoming Threat to Cyber Security," 2019 Academic Journal of Forensic Sciences ISSN: 2581-4273, 2019.

[4] Anthony Wong, "Cybersecurity - Threats Challenges Opportunities," Australian Computer Society Creative Commons Attribution-ShareAlike 4.0 International License, 2016.

[5] Phil Legg and Tim Blackman, "Tools and Techniques for Improving Cyber Situational Awareness of Targeted Phishing Attacks," International Conference on Cyber Situational Awareness, Data Analytics and Assessment (Cyber SA), 2019.

[6] Ravichandran.KandArulchelvan.S, "The Curve Fitting Model Analyzed the Survey of Crime News Awareness in India," 2017 Second International Conference on Recent Trends and Challenges in Computational Models (ICRTCCM), 2017.

[7] Hamid Zolfi, Hamidreza Ghorbani, and M. Hossein Ahmadzadegan, "Investigation and classification of cyber-crimes through IDS and SVM algorithm," 2019 Third International conference on I-SMAC (IoT in Social, Mobile, Analytics, and Cloud) (I-SMAC), 2019.

[8] Patrik Lif, Magdalena Granåsen, and Teodor Sommestad, "Development and validation of technique to measure cyber situation awareness," 2017 International Conference On Cyber Situational Awareness, Data Analytics And Assessment (Cyber SA), 2017.

[9] Farooq Azam, "The Global Challenge Of Human Trafficking \& Smuggling," 2004 Work Product Of The 122ND International Training Course Visiting Experts' Papers, United Nations Asia and Far East Institute(UNAFEI), 2004.

[10] Laviero Buono, "Fighting cybercrime through prevention, outreach, and awareness-raising," 2014 ERA Forum, 2014. 